\title{
ЕКСПЕРИМЕНТАЛЬНЕ ВИЗНАЧЕННЯ МІНІМАЛЬНОЇ НАПРУГИ СПРАЦЬОВУВАННЯ АВАРІЙНИХ РЕЛЕ ЗАЛІЗНИЧНОЇ АВТОМАТИКИ
}

\author{
Асп. О.Я. Куриленко (ДНУЗТ)
}

\section{ЭКСПЕРИМЕНТАЛЬНОЕ ОПРЕДЕЛЕНИЕ МИНИМАЛЬНОГО НАПРЯЖЕНИЯ СРАБАТЫВАНИЯ АВАРИЙНЫХ РЕЛЕ ЖЕЛЕЗНОДОРОЖНОЙ АВТОМАТИКИ}

Асп. Е.Я. Куриленко (ДНУЖТ)

\section{EXPERIMENTAL DETERMINATION OF THE MINIMUM OPERATING VOLTAGE OF ALARM RELAY FOR RAILWAY AUTOMATION}

\author{
Postgraduate E. Kurilenko DNUZT
}

Наведено методи обробки та результати експериментального визначення мінімальної напруги спрацьовування аварійних реле залізничної автоматики.

Ключові слова: реле, напруга спрачьовування, інтервал, допуск.

Представлены методы обработки и результаты экспериментального определения минимального напряжения срабатывания аварийных реле железнодорожной автоматики.

Ключевые слова: реле, напряжение срабатывания, интервал, допуск.

One of the factors determining the safety on the railways of Ukraine is a stable operation of the railway automation in conditions an unstable power supply. Emergency scheme of power supply for automation is realise by means of alarm relays, which are characterized by different response times and off at different voltages on the coil. The author carried out an experimental researches aimed to determine the minimum operating voltage alarm relay. Presented the methods of processing the experimental data and proved the usefulness of further studies on the average values of the studied variables.

Keywords: relay, operating voltage, interval, admission.

Вступ. Безпека руху на магістральних та промислових залізницях - це важливе завдання, вирішення якого забезпечують відповідні системи залізничної автоматики. Живлення цих систем здійснюється, як правило, від окремих ліній. При збої в роботі цих джерел системи автоматики переходять на аварійні джерела електричної енергії. Перехід 3 одного джерела на інше забезпечують так звані аварійні реле.

Внаслідок неякісної електричної енергії або пї імпульсного провалу виникають ситуації переходу живлення автоматики на аварійні джерела при наявності напруги на основній лінії. Така ситуація класифікується як відмова.

Дослідження у галузі живлення пристроїв залізничної автоматики та їх захисту присвячені роботи $[1,2]$, у яких, як правило, приділялась увага якості живильної електроенергії та шляхам підвищення іiі відповідних показників. Режимів роботи аварійних реле залізничної автоматики, які відповідають за перемикання з одного джерела живлення на 
інше, серед проаналізованих автором джерел інформації, майже не зустрічається.

Мета роботи. Провести дослідження 3 визначення мінімальної напруги спрацьовування аварійних реле залізничної автоматики.

Матеріал і результати досліджень. Напрямок досліджень пов'язаний 3 роботою аварійних реле в умовах неякісної електричної енергії систем живлення залізничної автоматики. Серед параметрів релейної апаратури виділимо номінальну напругу реле, мінімальну напругу спрацьовування реле, максимальне значення напруги відпускання реле та час відпускання реле при різних значеннях напруги на котушці реле.

Наведені матеріали присвячені експериментальному визначенню мінімальної напруги спрацьовування аварійних реле залізничної автоматики.

Передумовою проведення експерименту було те, що кількість експериментальних точок по кожному зразку реле повинна бути не менше 20, попередньо приймаючи, що закон розподілення значень випадкової величини в експериментальних точках, є нормальним [3].

На рис. 1 наведено значення мінімальної напруги спрацьовування реле типу АШ2-1440 (було знято двадцять експериментальних точок).

Напруга спрацьовування реле, яка досліджувалась досить суттєво відрізняється від напруги повного притягнення якоря реле. На відміну від останньої, напруга спрацьовування реле $\epsilon$ мінімальною напругою, при якій блокконтакти реле замикаються.

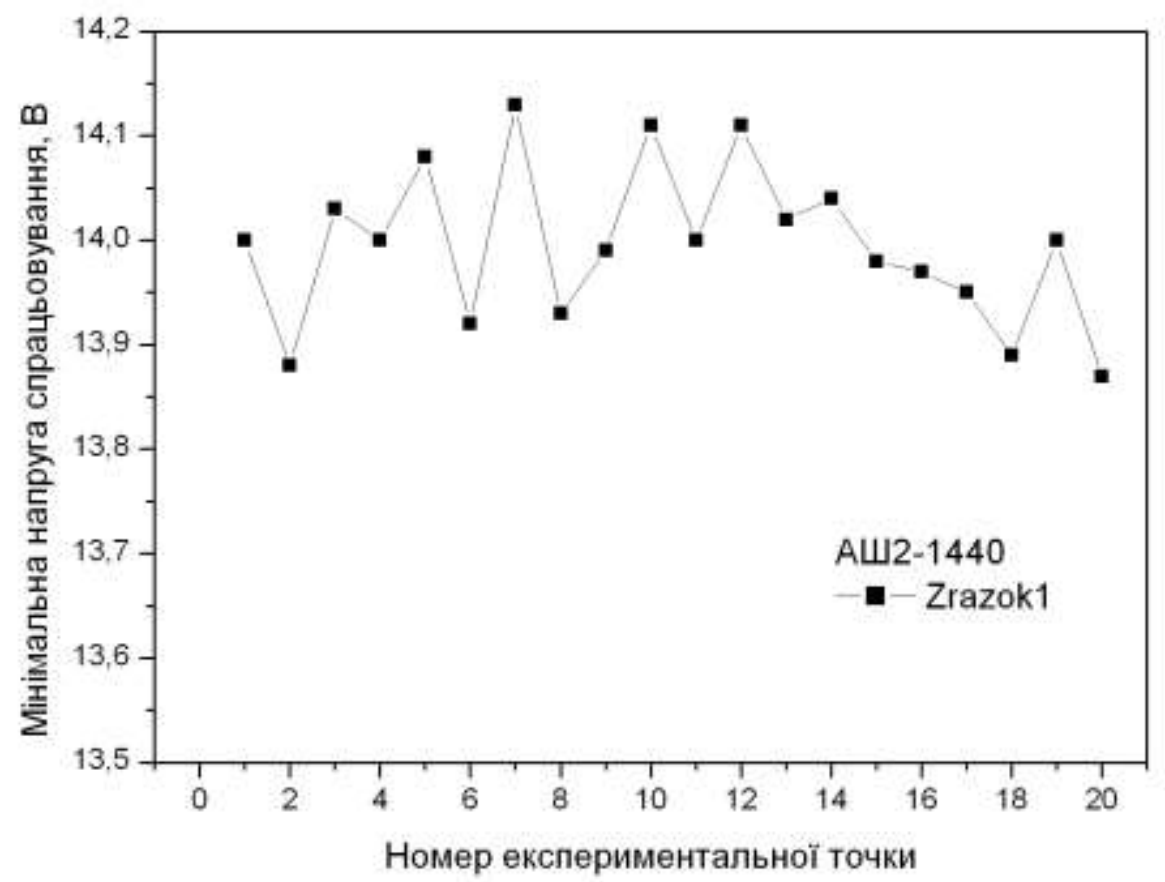

Рис. 1. Значення мінімальної напруги спрацьовування першого зразка аварійного реле типу АШ2-1440

Як видно 3 рис. 1, отримані під час проведення експерименту величини мають імовірнісний характер, тому доцільно провести відповідний аналіз отриманих результатів, використовуючи загальновідомі підходи [3-5]. Визначати 
закон розподілення досліджуваних величин немає сенсу, оскільки у кінцевому результаті потрібні тільки числові характеристики, які описують найбільш суттєві характеристики цього розподілення. Такою характеристикою, у нашому випадку, може бути математичне очікування.

Як відомо, при достатній кількості вимірювань середнє значення випадкової величини наближається за вірогідністю до свого математичного очікування і тому при практичних розрахунках може бути прийнято як таке. Таким чином, середні значення досліджуваних автором величин: середня мінімальна напруга спрацьовування, середня напруга відпускання та середній час відпускання аварійного реле $є$ шуканими числовими характеристиками .

Подані на рис. 1 величини мають розкид значень в діапазоні від $U_{\mathrm{cp}_{\min }}=13,87 \mathrm{~B} \quad$ до $\quad U_{\mathrm{cp}_{\max }}=14,13 \mathrm{~B}$. Діапазон розкиду напруги спрацьовування першого зразка аварійного реле $U_{\text {ср }}$ типу АШ2-1440 лежить $\quad$ у $\quad$ межах
$U_{\mathrm{cp}_{\max }}-U_{\mathrm{cp}_{\min }}=14,13-13,87=0,26 \mathrm{~B}$.

Виходячи із фізичних міркувань та спираючись на отримані під час проведення експериментів дані, доцільним є прийняти інтервал групування отриманих експериментальних величин напруги спрацьовування реле зі значенням $\Delta U_{\text {cp }}=0,05 \mathrm{~B}$.

Тоді діапазон зафіксованих значень напруги спрацьовування першого зразка аварійного реле типу АШ2-1440 при кількості експериментальних точок $n=20$ розбиваємо на $\left(U_{\mathrm{cp}_{\max }}-U_{\mathrm{cp}_{\min }}\right) / \Delta U_{\mathrm{cp}}=(14,13-13,87) / 0,05=5,2$ інтервалів групування. Отримане значення 5,2 не має фізичного сенсу, тому приймаємо кількість інтервалів рівним 6 при відповідній зміні нижньої та верхньої меж досліджуваного діапазону, а саме: $U_{\mathrm{cp}_{\min }}=13,85$ В та $U_{\mathrm{cp}_{\max }}=14,15 \mathrm{~B}$.

Тоді перший інтервал групування $U_{\text {ср1 }}$ складатиме:

$U_{\mathrm{cp} 1}=U_{\mathrm{cp}_{\min }}+\Delta U_{\mathrm{cp}}=13,85+0,05=13,9 \mathrm{~B}$,

тобто цей інтервал має межі від $U_{\mathrm{cp}_{\min }}=13,85 \mathrm{~B}$ до $U_{\mathrm{cp}_{\min }}+\Delta U_{\mathrm{cp}}=13,9 \mathrm{~B}$. Відповідно наступні інтервали матимуть межі:

$$
\begin{aligned}
& U_{\mathrm{cp} 2}=U_{\mathrm{cp} 1}+\Delta U_{\mathrm{cp}}=13,9+0,05=13,95 \mathrm{~B} ; \\
& U_{\mathrm{cp} 3}=U_{\mathrm{cp} 2}+\Delta U_{\mathrm{cp}}=13,95+0,05=14,00 \mathrm{~B} ; \\
& U_{\mathrm{cp} 4}=U_{\mathrm{cp} 3}+\Delta U_{\mathrm{cp}}=14,00+0,05=14,05 \mathrm{~B} ; \\
& U_{\mathrm{cp} 5}=U_{\mathrm{cp} 4}+\Delta U_{\mathrm{cp}}=14,05+0,05=14,10 \mathrm{~B} ; \\
& U_{\mathrm{cp} 6}=U_{\mathrm{cp} 5}+\Delta U_{\mathrm{cp}}=14,10+0,05=14,15 \mathrm{~B} .
\end{aligned}
$$

Для наочності деякі 3 отриманих величин для першого зразка аварійного реле типу АШ2-1440 наведемо у таблиці. 
Визначення середнього значення напруги спрацьовування першого зразка аварійного реле типу АШ2-1440

\begin{tabular}{|c|c|c|c|c|c|c|}
\hline Показник & \multicolumn{6}{|c|}{ Значення показника по інтервалах } \\
\hline $\begin{array}{l}\text { Межи інтервалу групування } \\
\text { випадкової величини } U_{\text {cp }} \text {, В }\end{array}$ & 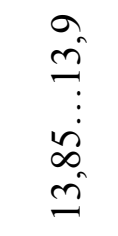 & 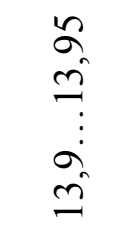 & 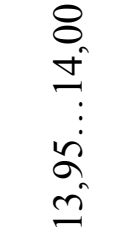 & 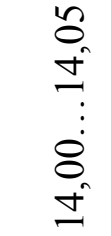 & $\begin{array}{l}0 \\
\vdots \\
\pm \\
\vdots \\
\vdots \\
0 \\
\pm \\
\vdots\end{array}$ & 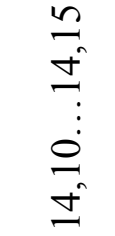 \\
\hline $\begin{array}{c}\text { Кількість зареєстрованих } \\
\text { значень напруги } U_{\text {сp }} \text { у } \\
\text { кожному діапазоні }\end{array}$ & 3 & 3 & 7 & 3 & 1 & 3 \\
\hline $\begin{array}{c}\text { Середнє значення напруги } \\
\text { спрацьовування аварійного } \\
\text { реле в інтервалі } \overline{U_{\mathrm{cp}_{i}}}, \text { В }\end{array}$ & 13,88 & 13,93 & 13,99 & 14,03 & 14,08 & 14,12 \\
\hline
\end{tabular}

У таблиці середнє значення напруги спрацьовування аварійного реле $\overline{U_{\text {cp }}}$ визначимо як відношення суми добутків середньої напруги $\overline{U_{\mathrm{cp}_{i}}}(i-$ порядковий номер інтервалу групування) у кожному інтервалі та кількості зареєстрованих значень напруги $n_{i}$ до загальної кількості експериментальних точок $n=20$ :

$$
\overline{U_{\mathrm{cp}}}=\sum_{i=1}^{6} \overline{U_{\mathrm{cp}_{i}}} n_{i} / n
$$

Таким чином:

$$
\overline{U_{\mathrm{cp}}}=\frac{\left(\begin{array}{l}
13,88 \cdot 3+13,93 \cdot 3+13,99 \cdot 7+ \\
+14,03 \cdot 3+14,08 \cdot 1+14,12 \cdot 3
\end{array}\right)}{20}=13,995
$$

За даними таблиці на рис. 2 наведемо гістограму розподілу випадкової величини $U_{\text {cp }}$, яка побудована за допомогою програми STATISTICA [6,7]. Червоною лінією на рис. 2 подано графік розподілу випадкової величини $U_{\text {ср }}$ при нормальному законі розподілення, який було нами прийнято як базовий, при визначенні необхідної кількості експериментальних точок. Побудована гістограма та нормальний закон розподілення відповідають один одному, тобто кількість необхідних експериментальних точок обрана правильно.

Загалом автором було досліджено по три зразки кожного з аварійних реле.

На рис. 3 наведено результати експериментального визначення мінімальної напруги спрацьовування трьох зразків аварійного реле типу АШ2-1440.

Аналогічно до рис. 2 подамо гістограми розподілу випадкової величини мінімальної напруги спрацьовування для другого та третього зразків аварійного реле типу АШ2-1440 (рис. 4, 5).

Для перевірки адекватності отриманих експериментальних даних відмітимо, що проведена обробка результатів експериментів за допомогою програми STATISTICA дозволила встановити, що середнє значення мінімальної напруги спрацьовування першого зразка дорівнює $13,995 \mathrm{~B}$; другого - 13,27 В; третього - 13,52 В. Середнє цих трьох значень мінімальної напруги спрацьовування складатиме:

$$
\frac{13,995+13,27+13,52}{3}=13,6 \text { B. }
$$




\section{Електричний транспорт}

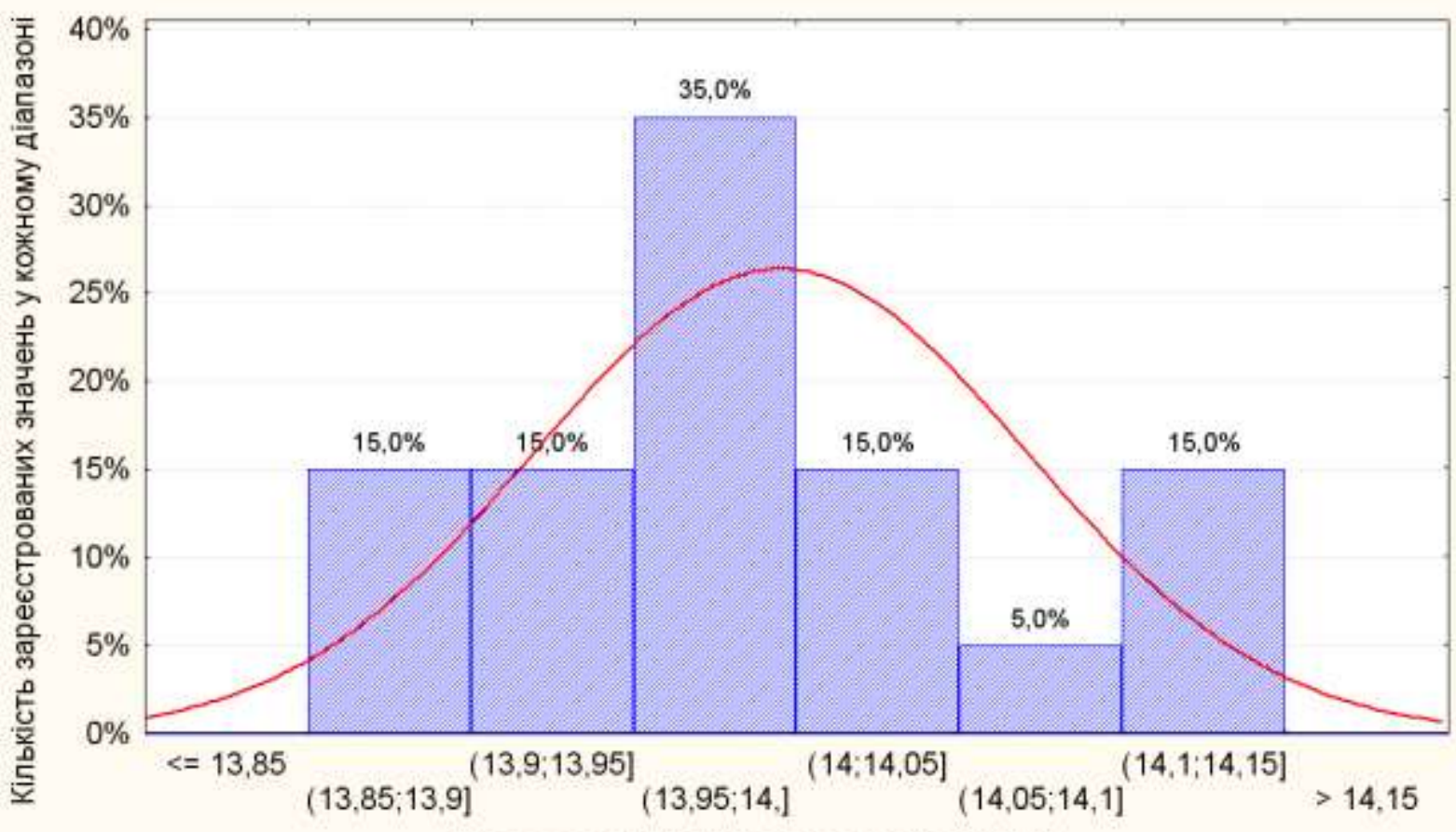

Iнтервали групування випадкової величини

Рис. 2. Гістограма розподілу випадкової величини мінімальної напруги спрацьовування першого зразка аварійного реле типу АШ2-1440

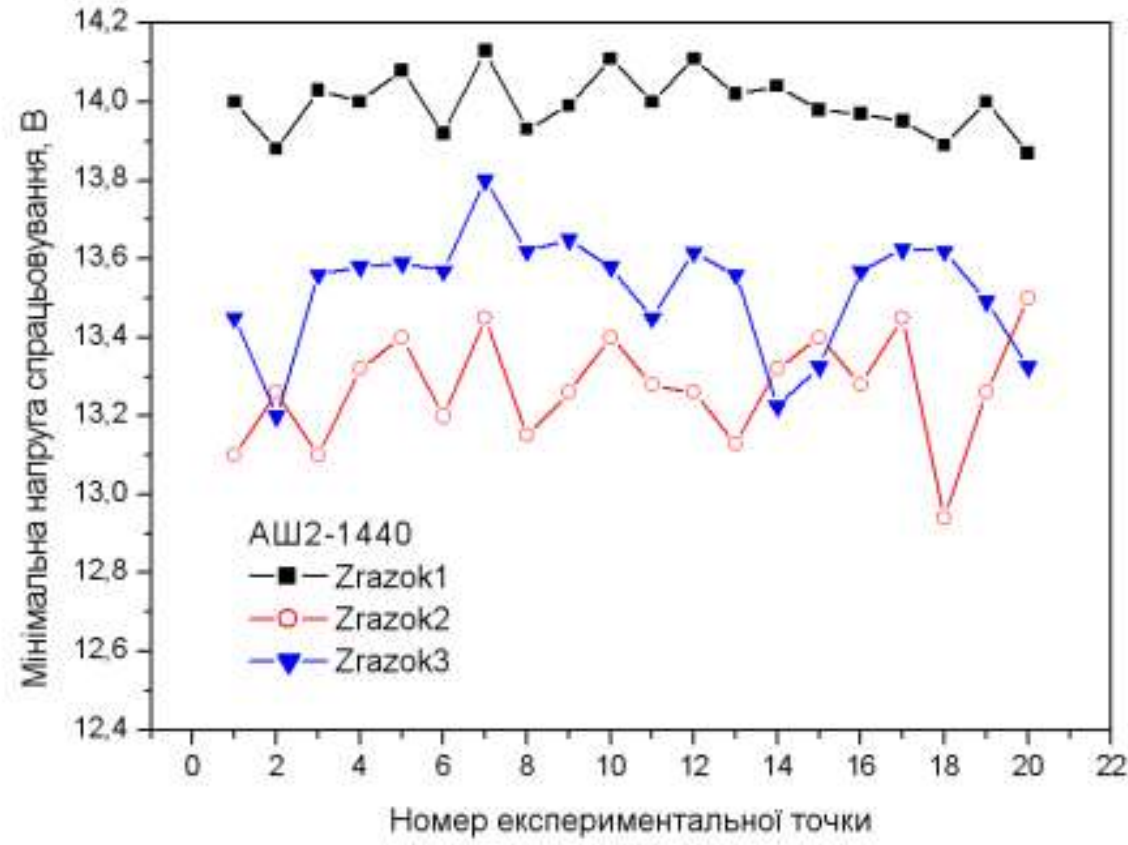

Рис. 3. Значення мінімальної напруги спрацьовування трьох зразків аварійного реле типу АШ2-1440 


\section{Електричний транспорт}

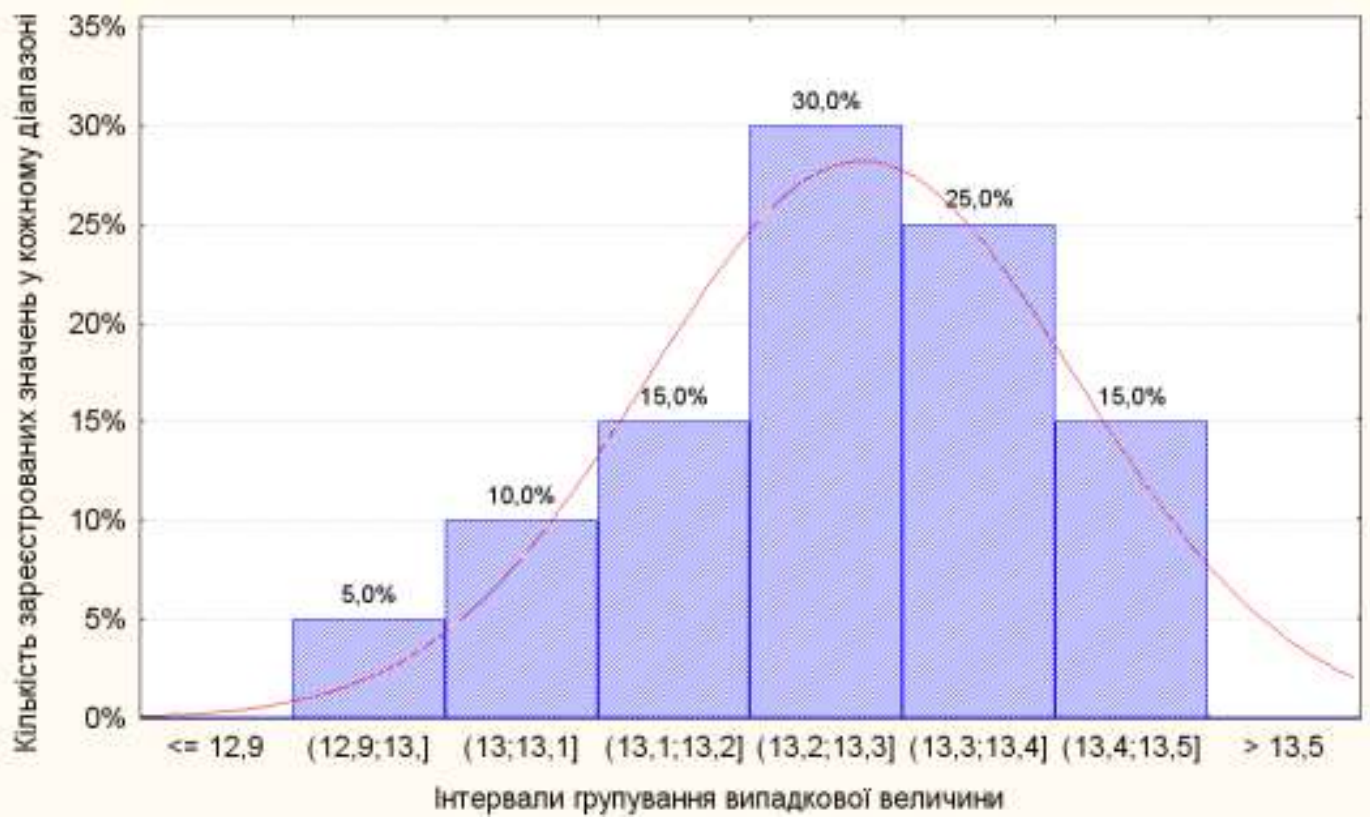

Рис. 4. Гістограма розподілу випадкової величини мінімальної напруги спрацьовування другого зразку аварійного реле типу АШ2-1440

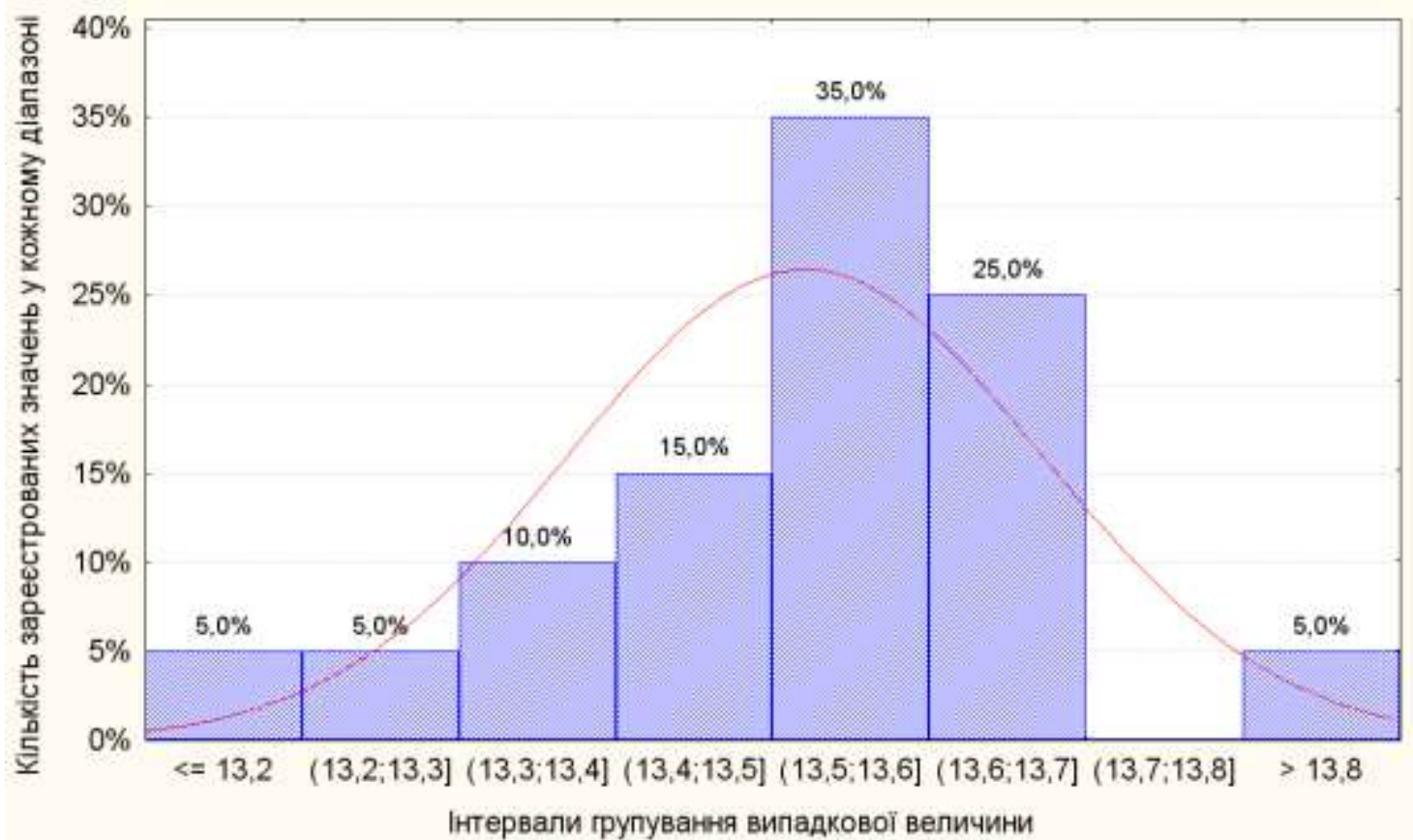

Рис. 5. Гістограма розподілу випадкової величини мінімальної напруги спрацьовування третього зразка аварійного реле типу АШ2-1440

Відхилення мінімальної напруги спрацьовування першого зразка від середнього значення становить: $\frac{|13,6-13,995|}{13,995} \cdot 100 \%=2,8 \%$. Для другого та третього зразків відповідні відхилення 
становлять: 2,43 і 0,56\%. Таким чином, взаємне відхилення середніх значень мінімальної напруги спрацьовування зразків аварійних реле, що досліджувались не перевищує загальноприйняте значення у $10 \%$.

Висновки. Проаналізовано понад двадцять типів аварійних реле, які експлуатуються на залізницях України. Отримані дані $\epsilon$ основою для подальших досліджень 3 визначення впливу неякісної електричної енергії та провалів напруги у живильних лініях на пристрої залізничної автоматики.

\section{Список використаних джерел}

1. Сиченко, В.Г. Електроживлення систем залізничної автоматики [Текст]: монографія / В.Г. Сиченко, В.І. Гаврилюк. - Дніпропетровськ: Вид-во Маковецький, 2009. - 372 с.

2. Костроминов, А.М. Защита устройств железнодорожной автоматики и телемеханики от помех [Текст] / А.М. Костроминов. - М.: Транспорт, 1997. - 192 с. $576 \mathrm{c}$.

3. Вентцель, Е.С. Теория вероятностей [Текст] / Е.С. Вентцель. - М.: Наука, 1969. -

4. Красовский, Г.И. Планирование эксперимента [Текст] / Г.И. Красовский, Г.Ф. Филаретов. - Минск: Изд-во БГУ, 1982. - 302 с.

5. Справочник по теории вероятностей и математической статистике [Текст] / [Королюк В.С., Портенко Н.И., Скороход А.В., Турбин А.Ф.]. - М.: Наука, 1985. - 640 с.

6. Халафян, A.A. STATISTICA 6. Статистический анализ данных [Текст] / А.А. Халафян. - М.: Бином-Пресс, 2007. - 512 с.

7. Вуколов, Э.А. Основы статистического анализа. Практикум по статистическим методам и исследований операций с использованием пакетов STATISTICA и EXCEL [Tекст] / Э.А. Вуколов. - М.: Форум, 2008. - 464 с.

Куриленко О.Я., аспірантка кафедри електропостачання залізниць, Дніпропетровський національний університет залізничного транспорту ім. акад. В. Лазаряна.

Kurilenko Elena, postgraduate 